\title{
The Potential Impact Radius of a Natural Gas Transmission Line and Real Estate Valuations: A Behavioral Analysis
}

\author{
By \\ Charles Hilterbrand Jr., University of South Florida
}

This study intended to address the question, "How would a purchase price be impacted if a seller provided buyers a notice that the residential property that has been listed for sale is located within a Potential Impact Radius (PIR) of a natural gas transmission line?" Does the notice of being located within the PIR affect the purchase value a buyer is willing to offer for a residential property? Does the perceived risk associated with PIR affect the amount a potential buyer would offer?

According to the U.S. Department of Transportation's Pipeline and Hazardous Mate-

rials Safety Administration (PHMSA), A Potential Impact Radius (PIR) is the radius of a circle within which the potential failure of a pipeline could have significant impact on people or property. (49 CFR \$192.903 (Subpart O) This designation of properties located within a PIR requires pipeline operators to provide the government with a maintenance schedule to ensure public safety. The designation of a property within a PIR is not required to be disclosed to the present landowner or any future purchasers of residential property within the PIR. This study is an attempt to ascertain what would happen if this designation was required to be disclosed to a potential residential real estate purchaser.
A thorough literature review of this subject showed that the present academic and practice literature states that the proximity of a residential property to a natural gas transmission line does not impact sales prices. A review of this literature did not find a reference to a Potential Impact Radius (PIR).
How would a purchase price be impacted if a seller provided buyers a notice that the residential property that has been listed for sale is located within a Potential Impact Radius (PIR) of a natural gas transmission line?
The methodological design for this study was a contingent valuation method associated with an experimental design (for similar examples, see Lane, Seiler $\&$ Seiler, 2013; Seiler 2014; Seiler 2018). Three hypotheses were examined:
Hl: Notice that a single-family residential home is located near natural gas transmission pipeline impacts a potential purchaser's perceived value.

$\mathrm{H} 2$ : Notice that a single-family residential home is located within a Potential Impact Radius of a natural gas transmission pipeline impacts a potential purchaser's perceived value.

H3: Notice that a single-family residential home is located within a Potential Impact Radius of a natural gas transmission pipeline has a greater impact on a potential purchaser's perceived value than notice that a single-family residential home is located near natural gas transmission pipeline.

Keywords: Easement, Right of Way, Pipeline, Land Use, Disclosure, High Consequence Area

Copyright $\odot$ 2020, Charles Hilterbrand Jr. This article is published under a Creative Commons BY-NC license. Permission is granted to copy and distribute this article for non-commercial purposes, in both printed and electronic formats 


\section{Findings}

A series of $t$-tests were performed that compared the control group, the pipeline group, and the PIR group. No statistically significant difference was found in the fair offer value mean between the control group and the group with notice the residence is located within 500 feet of a natural gas transmission line was found. No statistically significant difference was found in the fair market value between the group with notice the residence is located within 500 feet of a natural gas transmission line and the group with notice the residence is located within the potential impact radius (PIR) of a natural gas transmission line was found. A statistical significance was found where the control group was compared to the group with notice the residence is located within the potential impact radius (PIR). The t-test, which included these two groups, confirmed the difference in fair offer value mean of $1.8 \%$ was significant.

Pearson's chi-square tests were also performed which distinguished the PIR group from the pipeline group. The Pearson's chi-square tests also showed that the PIR group was less likely to see themselves as purchasers of the subject property. This result may be due to the type of house, location, or price point. However, this result also may be a sign that once this group was notified that a residence is located within a PIR, the respondents within that group experienced an increase in perceived risk associated with the residence and were less interested in the home.

\section{Conclusions}

As prior literature has stated, proximity to a natural gas transmission line provided minimal to no impact on the value of a residential property. This study does not contradict the prior literature.

However, there appears to be a statistical significance when a control group is compared to a treatment group providing notice that the residence is located within a PIR.

Additional research should be performed in this area to see if this statistical significance can be duplicated, if additional cues can be added, if other models and methods can produce similar outcomes, or if a change in the types and locations of the houses affects the outcome.

\section{Where to Find Out More}

The author may be contacted by email for additional information at chilterbrand@bus.olemiss.edu.

\section{Methodology}

Qualtrics survey was performed using respondents in 16 counties in southwest Ohio. The respondents were randomly segregated into three groups. Each respondent was shown one of three versions of a short video home tour presentation. A control group was presented a video tour without any residential disclosure notice. A second group, refereed to as the pipeline group, was presented a video tour with an audible notice that the residence is located within 500 feet of a natural gas transmission line. A third group, referred to as the PIR group, was presented a video tour with an audible notice that the residence is located within the potential impact radius (PIR) of a natural gas transmission line. Each respondent was then asked to state a fair offer value for the residential property shown in their respective video. Additional questions concerning interest in the subject house and demographic information from the respondents were asked to aid in the statistical analysis.

\section{References}

Lane, M., Seiler, M., \& Seiler, V. (2013). Measuring the impact of power lines on home prices: an experimental approach. Real Estate Finance, Fall.

Seiler, M.J. (2014). Power Lines and Perceived Home Prices: Isolating Elements of Easement Rights and Noise Pollution. Journal of Sustainable Real Estate, 6(2), 47-61.

Seiler, M. J. (2018). Using Behavioral Real Estate Techniques to Determine Just Compensation in Eminent Domain Partial Taking Cases. Real Estate Finance, (3), 121.

\section{Review}

This article was accepted under the constructive peer review option. For futher details, see the descriptions at:

http://mumabusinessreview.org/peer-review-options/ 


\section{Author}

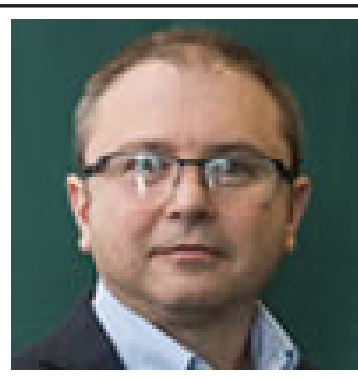

Charles Hilterbrand Jr. is a real estate attorney in Ohio whose career has spanned more than two decades. The shale-oil boom in Ohio changed the direction of his law practice and in 2012, Hilterbrand switched his professional focus from commercial and residential real estate title and insurance to oil and gas real estate title examination and opinion. He received a bachelor's degree in political science and his law degree from the University of Akron. He earned an MBA with a concentration in finance from Kent State University and a master's in tax law from Case Western Reserve University's School of Law. He received his Doctor of Business Administration degree from the University of South Florida's Muma College of Business in 2019. 